\title{
Implementasi Algoritma Decision Tree_J48 untuk Memprediksi Resiko Kredit pada Koperasi Simpan Pinjam (Studi Kasus : Kofipindo Lubuk Pakam)
}

\author{
Kristin Sinaga $^{1}$, Efori Buulolo ${ }^{2}$, Berto Nadeak $^{3}$ \\ 1,2,3Program Studi Teknologi Informatika STMIK Budi Darma,Medan, Indonesia \\ Email: ${ }^{1}$ kristinsinaga456@gmail.com, ${ }^{2}$ buuloloefori21@gmail.com ${ }^{3}$ bertonadeak@gmail.com
}

\begin{abstract}
Abstrak
Berkembangnya era modern membuat banyak orang semakin terpengaruh dalam mengelola bisnis khususnya pada lembaga keuangan salah satunya adalalah kredit pada koperasi kofipindo. Kredit merupakan hal yang paling utama pada koperasi simpan pinjam dan menjadi hal yang berpengaruh terhadap kesehatan koperasi tersebut. Namun jika terjadi masalah manajemen yang sembarangan memberikan kredit akan berisiko bagi pihak perusahaan,yakni akan terjadi macet dari nasabah dan tidak tertagih. Untuk mengatasi permasalahan diatas diperlukan sebuah metode. Adapun teknik yang dapat dimanfaatkan dalam proses mengolah data adalah klasifikasi dengan algoritma J48. Algoritma J48 adalah salah satu algoritma klasifikasi yang diterapkan pada teknik decision tree yang diproses menggunakan information gain. Dalam memilih atribut untuk pemecah obyek dalam beberapa kelas harus dipilih atribut yang menghasilkan information gain paling besar atribut dengan nilai information gain tertinggi akan dipilih sebagai parent bagi node selanjutnya.
\end{abstract}

Kata Kunci: Prediksi resiko kredit, Algoritma J48

\section{Abstract}

The development of the modern era has made many people more influenced in managing business, especially in financial institutions, one of which is credit at the Kofipindo cooperative. Credit is the most important thing in a savings and loan cooperative and it has an effect on the health of the cooperative. However, if there is a management problem that carelessly provides credit, it will be risky for the company, namely there will be a loss of customers and not collectible. To overcome the problems above, a method is needed. The technique that can be utilized in the process of processing data is the classification with the $\mathrm{J} 48$ algorithm. J48 algorithm is a classification algorithm applied to decision tree techniques that are processed using information gain. In selecting attributes for object breakers in several classes, the attribute that produces the greatest information gain with the highest information gain value will be chosen as the parent of the next node.

Keywords: Credit risk prediction, Algorithm J48

\section{PENDAHULUAN}

Koperasi KOFIPINDO adalah sebuah lembaga yang bergerak dalam bidang keuangan dimana paranasabahnya merupakan masyarakat. Dalam hal ini masyarakat dapat menyimpan atau meminjam keuangan. Sampai saat ini Kofipindo masih berada diJln. Besar pantai Labu Pw Asri No.100 Lubuk Pakam dengan badan Hukum no/22/bh/kwk.2/xll/1995.

Data Mining adalah sebagai proses untuk mendapatkan informasi yang berguna dari gudang basis data yang besar. Data mining juga dapat diartikan sebagai pengekstrakan informasi baru yang diambil dari bongkahan data besar yang membantu dalam pengambilan keputusan. Salah satu teknik yang dibuat dalam data mining adalah bagaimana cara menelusuri data yang ada untuk membangun sebuah model, kemudian menggunakan model tersebut agar dapat mengenali pola data yang lain yang tidak berada pada basis data yang tersimpan.

Berdasarkan data yang telah diperoleh sebelumnya pada Koperasi Kofipindo Lubuk Pakam bahwa koperasiini dapat meminjamkan uang kepada nasabah. dalam hal ini kolektor akan melakukan tinjauan terlebih dahulu kelapangan. jika sesuai dengan persyaratan dari pihak koperasi maka kolektor akan memberikan pinjaman sesuai dengan usaha yang dimiliki oleh nasabah. Namun, karena faktor ekonomi sebagian nasabah ada yang tidak bertanggung jawab ataupun penagihan macet dan jika terjadi dari waktu ke waktu hal ini berpengaruh terhadap keuntungan atau kerugian pada Koperasi simpan pinjam Kofipindo. Untuk mengatasi masalah diatas penulis melakukan prediksi resiko kredit dengan menggunakan algoritma j48 untuk mengetahui apa saja faktor yang mempengaruhi kredit macet pada koperasi Kofipindo.Output dari algoritma J48 berbentuk pohon keputusan, dari pohon keputusan tersebut dapat disimpulkan faktor apa saja yang menyebabkan terjadinya resiko kredit.[1][2]

\section{TEORITIS}

\subsection{Implementasi}

Dalam kenyataannya, implementasi merupakan proses untuk melaksanakan ide, program atau seperangkat aktivitas baru dengan harapan orang lain dapat menerima dan melakukan perubahan. Dalam konteks implementasi kurikulum pendekatan-pendekatan yang telah dikemukakan diatas memberikan tekanan pada proses, suatu aktivitas yang digunakan untuk mentransfer ide atau gagasan, program yang dituangkan dalam bentuk kurikulum desain (tertulis) agar dilaksanakan sesuai dengan desain tersebut. Masing-masing pendekatan itu mencerminkan tingkat pelaksanaan yang berbeda[1].

\subsection{Data Mining}


Data mining adalah proses yang mempekerjakan satu atau lebih teknik pembelajaran komputer (machine learning) untuk menganalisa dan mengekstrak pengetahuan secara otomatis. Data mining berisi pencarian trend atau pola yang diinginkan dalam database besar untuk membantu pengambilan keputusan diwaktu yang akan datang. Pola-pola ini dikenali oleh perangkat tertentu yang dapat memberikan suatu analisa data yang berguna dan berwawasan yang kemudian dapat dipelajari dengan lebih teliti, yang mungkin saja menggunakan perangkat pendukung keputusan lainnya[3][4][5][6].

\subsection{Algoritma J48}

Algoritma J48 adalah salah satu jenis classifier pada metode klasifikasi dalam data mining dan bagian dari C4.5 decision tree yang sederhana. $\mathrm{J} 48$ membangun sebuah pohon keputusan berdasarkan pada seperangkat input data yang berlabel. Pohon keputusan adalah model prediksi yang digunakan struktur pohon atau struktur berhirarki. Konsep dari pohon keputusan adalah mengubah data menjadi pohon keputusan dan aturan-aturan keputusa Berikut ini tahapan algoritma J48 [1]:

Data yang dimiliki harus disusun menjadi sebuah tabel berdasarkan kasus dan jumlah responden sebelum dilakukan perhitungan untuk mencari nilai entropy dan gain.

$\operatorname{Entropy}(S)=\sum_{i=0}^{n}-\mathrm{pi} * \log ^{2} \quad p i$

Rumus (2) merupakan rumus yang digunakan dalam perhitungan entropy yang digunakan untuk menentukan seberapa informatif atribut tersebut. Berikut keterangannya:

$S$ :Himpunan kasus

$n$ :Jumlah partisi $S$

pi :Jumlah kasus pada partisi ke

$-\operatorname{Gain}(S, A)=\operatorname{Entropy}(S)-\sum_{i=1}^{n} \frac{|s i|}{|s|} * \operatorname{Entropy}(S i)$

Rumus (1) merupakan rumus yang digunakan dalam perhitungan gain setelah melakukan perhitungan entropy. Berikut keterangannya:

$S \quad$ : Himpunan kasus

A : Atribut

$n$ : Jumlah partisi atribut A

$|S i|: J u m l a h$ kasus pada partisi ke-i

$|S|$ :Jumlah kasus dalam $S .[1]$

\section{ANALISA DAN PEMBAHASAN}

\subsection{Analisa Masalah}

Pada bab ini Analisa yang dilakukakan adalah analisa data untuk memprediksi resiko kredit pada Koperasi Kofipindo Lubuk Pakam. Berdasarkan data yang telah diperoleh sebelumnya pada Koperasi Kofipindo Lubuk Pakam bahwa koperasi ini dapat meminjamkan uang kepada nasabah. Dalam hal ini kolektor akan melakukan tinjauan terlebih dahulu kelapangan. jika sesuai dengan persyaratan dari pihak koperasi maka kolektor akan memberikan pinjaman sesuai dengan usaha yang dimiliki oleh nasabah. Namun, karena faktor ekonomi sebagian nasabah ada yang tidak bertanggung jawab ataupun penagihan macet dan jika terjadi dari waktu ke waktu hal ini berpengaruh terhadap keuntungan atau kerugian pada Koperasi simpan pinjam Kofipindo. Untuk mengatasi masalah diatas penulis melakukan analisa untuk memprediksi resiko kredit dengan menggunakan algoritma j48 untuk mengetahui apa saja faktor yang mempengaruhi kredit macet pada koperasi Kofipindo.Output dari algoritma J48 berbentuk pohon keputusan, dari pohon keputusan tersebut dapat disimpulkan faktor apa saja yang menyebabkan terjadinya resiko kredit.

Adapun analisa yang dilakukan berdasarkan data-data yang ada pada Koperasi Kofipindo, dimana data-data nasabah kredit diambil pada tahun 2018 dengan analisa data 20 jenis data beserta atributnya. Berikut ini adalah data nasabah kredit pada tahun 2019.[2]

\subsection{Pre-Procesing Data}

Procesing Data yang diguinakan untuk membentuk pohon keputusan. Sedangkan pohon keputusan dapat diartikan suatu cara untuk memprediksi atau mengklarifikasi yang sangat luas. Pemrosesan data mining menggunakan algoritma J48 degngan melakukan pengumpulan data dan mengklasifikasikan data menggunakan representasi struktur pohon keputusan dimana setiap node mempresentasikan nilai dari atribut dan dan mempresentasikan node. Data yang dimiliki akan disusun menjadi sebuah tabel dan jumlah responden sebelum dilakukan perhitungan untuk mencari nilai entropy dan gain. Adapun tahap yang digunakan pada algoritma J48 adalah:

1. Pilih atribut sebagai akar. 
2. Buat cabang untuk tiap-tiap nilai.

3. Bagi kasus dalam cabang.

4. Ulangi proses untuk setiap cabang sampai semua kasus pada cabang memiliki kelas yang sama.

\subsection{Analisa Data}

Adapun analisa yang dilakukan berdasarkan data-data yang ada pada Koperasi Kofipindo Lubuk Pakam, dimana data-data kredit yang digunakan adalah tahun 2019. Data-data kredit yang digunakan untuk analisa data 20 jenis data nasabah kredit beserta atributnya. Adapun tabel pada data Koperasi Kofipindo Lubuk Pakam tahun 2019 adalah sebagai berikut:

Tabel 1. Data prediksi resiko kredit tahun 2019

\begin{tabular}{lccccccc}
\hline No & Nama & Pekerjaan & Besar pinjaman & Besar tanggungan & Pendapatan & Aset & $\begin{array}{c}\text { Resiko } \\
\text { Kredit }\end{array}$ \\
\hline 1. & Bu wati & Petani & besar & Sedang & Besar & Besar & $?$ \\
2. & Bu tuti ani & Wiraswasta & Kecil & kecil & Besar & Kecil & $?$ \\
3. & Bu Lina B & Wiraswasta & Besar & sedang & Besar & Besar & $?$ \\
4. & Ibu Nurhayati & Wiraswasta & Kecil & Sedang & Besar & Besar & $?$ \\
5. & Ibu Nurmala & Wiraswasta & Kecil & Sedang & Besar & Besar & $?$ \\
6. & Ka evi & Honorer & Besar & Besar & Besar & Besar & $?$ \\
7. & Bu iyen & Wiraswasta & Kecil & Kecil & Kecil & Besar & $?$ \\
8. & BuWagini & Wiraswasta & Kecil & Besar & Sedang & Besar & $?$ \\
9. & BuSugiani & Honorer & Besar & Kecil & Kecil & Besar & $?$ \\
10. & Bu Puji & Petani & Kecil & Kecil & Kecil & Kecil & $?$ \\
11. & Nurcahaya & Petani & Kecil & Sedang & Besar & Besar & $?$ \\
12. & Ka Peni & Wiraswasta & Kecil & Sedang & Besar & Kecil & $?$ \\
13. & Bu iyus & Wiraswasta & Kecil & Besar & Besar & Kecil & $?$ \\
14. & Bu Lis & Wiraswasta & Kecil & Kecil & Kecil & Besar & $?$ \\
15. & Wulan & Honorer & Kecil & Sedang & Besar & Kecil & $?$ \\
16. & Ka Juli & Petani & Kecil & Sedang & Kecil & Kecil & $?$ \\
17. & Rina & Wiraswasta & Besar & Sedang & Kecil & Besar & $?$ \\
18. & Tatik & Petani & Kecil & Kecil & Kecil & Besar & $?$ \\
19. & Bu Renggo & Petani & Kecil & Sedang & Besar & Besar & $?$ \\
20. & Mak Enjel & Wiraswasta & Kecil & Sedang & Kecil & Kecil & $?$ \\
\hline
\end{tabular}

Untuk memprediksi resiko kredit pada data nasabah tahun 2019 diatas, maka digunakan data-data sebelumnya sebagai acuan dalam pencarian rule/aturan.

1. Proses pencarian rule dengan menggunakan data tahun 2018

Berikut adalah data klasifikasi data nasabah kofipindo tahun 2018 yang digunakan sebagai Rule untuk memprediksi data Nasabah Kofipindo tahun 2019 :

Tabel 2. Data Klasifikasi Nasabah Kredit tahun 2018

\begin{tabular}{|c|c|c|c|c|c|c|c|}
\hline No & Nama & Pekerjaan & Besar pinjaman & Besar tanggungan & Pendapatan & Aset & Keterangan \\
\hline 1. & Ngatinem & Petani & $>5$ Juta & 4 Juta & $>5$ Juta & $>200$ Juta & Lancar \\
\hline 2. & Bu Juli & Wiraswasta & $<5$ Juta & 3 Juta & $>5$ Juta & $<200$ Juta & Lancar \\
\hline 3. & Bu Lina B & Wiraswasta & $>5$ Juta & 5 Juta & $>5$ Juta & $>200$ Juta & Lancar \\
\hline 4. & Bu Atik & Wiraswasta & $<5$ Juta & 4,5 Juta & $<5$ Juta & $>200$ Juta & Tidak lancar \\
\hline 5. & Ibu Nurmala & Wiraswasta & $<5$ Juta & 4 Juta & $>5$ Juta & $>200 \mathrm{Juta}$ & Lancar \\
\hline 6. & Bu Sugiani & Honorer & $>5$ Juta & 6 Juta & $>5$ Juta & $<200$ Juta & Lancar \\
\hline 7. & Bu iyen & Wiraswasta & $<5$ Juta & 2 Juta & $<5$ Juta & $>200$ Juta & Lancar \\
\hline 8. & BuWagini & Wiraswasta & $<5$ Juta & 7 Juta & $>5$ Juta & $>200$ Juta & Lancar \\
\hline 9. & BuSugiani & Honorer & $>5$ Juta & 2 Juta & $<5$ Juta & $>200$ Juta & Lancar \\
\hline 10. & Bu Puji & Petani & $<5$ Juta & 2,5 Juta & $<5$ Juta & $<200$ Juta & Lancar \\
\hline 11. & Nurcahaya & Petani & $<5$ Juta & 4 Juta & $>5$ Juta & $>200$ Juta & Lancar \\
\hline 12. & Bu wanti & Wiraswasta & $<5$ Juta & 5 Juta & $>5$ Juta & $<200$ Juta & Lancar \\
\hline 13. & Bu iyus & Wiraswasta & $<5$ Juta & 6 Juta & $>5$ Juta & $<200$ Juta & Lancar \\
\hline 14. & $\mathrm{Bu}$ Lis & Wiraswasta & $<5$ Juta & 3 Juta & $<5$ Juta & $>200$ Juta & Lancar \\
\hline 15. & Wulan & Honorer & $<5$ Juta & 4 Juta & $<5$ Juta & $<200$ Juta & Tidak lancar \\
\hline 16. & Ka Juli & Petani & $<5$ Juta & 4 Juta & $>5$ Juta & $<200$ Juta & Lancar \\
\hline 17. & Kiki amel & Wiraswasta & $<5$ Juta & 4 Juta & $<5$ Juta & $>200$ Juta & Tidak Lancar \\
\hline 18. & Tatik & Petani & $<5$ Juta & 3 Juta & $<5$ Juta & $>200$ juta & Tidak lancar \\
\hline 19. & Bu Renggo & Petani & $<5$ Juta & 4 Juta & $>5 \mathrm{Juta}$ & $>200$ juta & Lancar \\
\hline 20. & Ka peni & Wiraswasta & $<5$ Juta & 4 Juta & $<5$ Juta & $<200$ juta & Tidak lancar \\
\hline
\end{tabular}

Berikut ini merupakan rumus untuk perhitungan nilai entrophy, seperti pada persamaan satu berikut:

Entrophy $(\mathrm{S})=\sum_{i=0}^{n}-p i * \log 2 p i$ 
Keterangan :

$\begin{array}{ll}\mathrm{S} & : \text { Himpunan kasus } \\ n & : \text { Jumlah Partisi S } \\ p i & : \text { Jumlah kasus pada partisi ke }-\mathrm{I}\end{array}$

Gain $(\mathrm{S}, \mathrm{A})=$ Entrophy $(S)-\sum_{i=1}^{n} \frac{|S i|}{|S|} *$ Entrophyi $(S i)$

Keterangan :

S : Himpunan kasus

n : Jumlah partisi atribut A

$|\mathrm{Si}| \quad$ : Jumlah kasus pada partisi ke-i

$|\mathrm{S}| \quad$ : Jumlah kasus dalam S

Langkah selanjutnya menghitung nilainya, berikut ini adalah rekapitulasi nilai entropy dan gainnnya:

Tabel 4.14 Rekapitulasi Hasil

Node

Keterangan Kasus Lancar Tidak lancar Entropy Gain

$1 \quad$ Pendapatan $=$ kecil Dan Besar tanggungan $=$ kecil Dan pekerjaan=petani

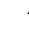

Besar pinjaman

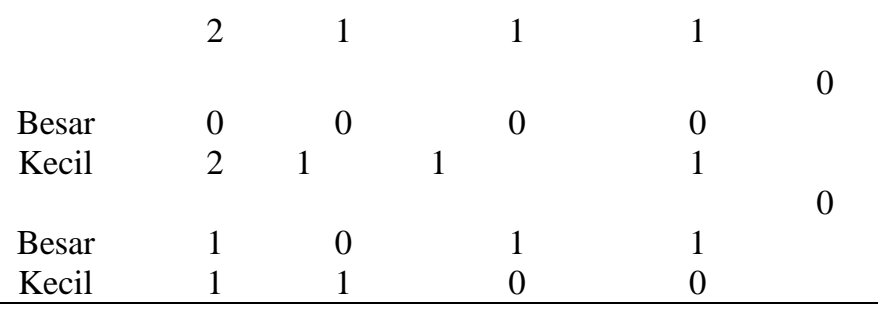

Pada tabel diatas menunjukkan bahwa kriteria Besar pinjaman memiliki Gain yang paling tinggi. Untuk fase selanjutnya adalah pembentukan Tree (pohon keputusan). Berikut ini adalah Tree dari nilai Entropy dan Gainny.

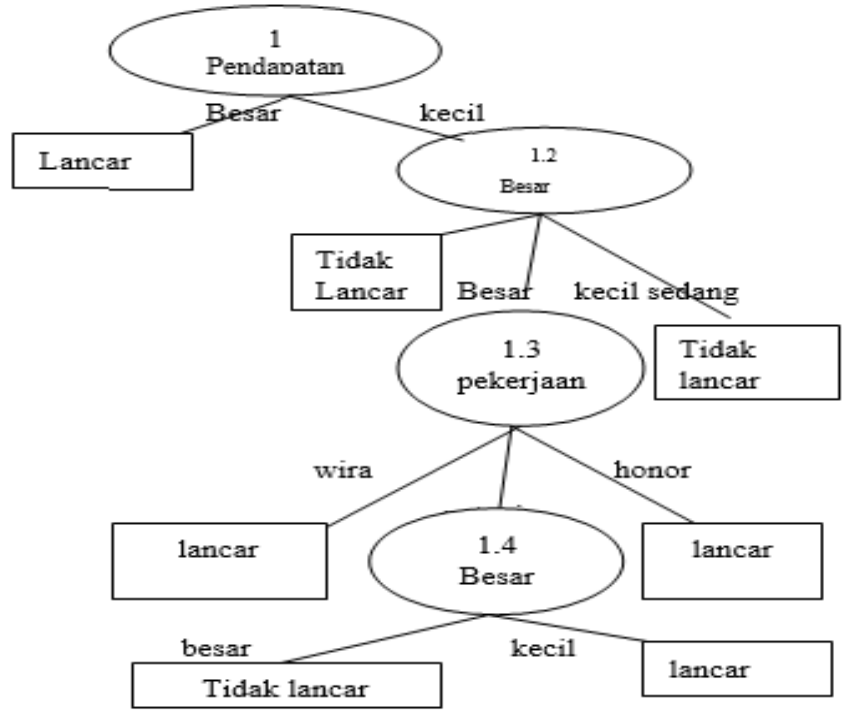

Gambar 1. Pohon Keputusan

Maka basis pengetahuan atau Rule yang terbentuk yaitu;

1. Jika pendapatan=besar maka hasil = lancar

2. Jika pendapatan=kecil dan besar tanggungan $=$ besar maka hasil $=$ tidak lancar

3. Jika pendapatan $=$ kecil besar tanggungan $=$ kecil dan pekerjaan $=$ wiraswasta maka hasil $=$ lancar

4. Jika pendapatan $=$ kecil besar tanggungan $=$ kecil dan pekerjaan $=$ petani dan besar pinjaman=besar maka hasil $=$ tidak lancar

5. Jika pendapatan $=$ kecil besar tanggungan $=$ kecil dan pekerjaan $=$ petani dan besar pinjaman=kecil maka hasil $=$ lancar

6. Jika pendapatan $=$ kecil besar tanggungan $=$ kecil dan pekerjaan $=$ honor maka hasil $=$ lancar

7. Jika pendapatan= kecil besar tanggungan =sedang maka hasil=tidak lancar

\section{KESIMPULAN}


Berdasarkan uraian pada bab-bab sebelumnya, maka penulis mengambil keputusan sebagai berikut.

1. Dengan menggunakan algoritma j48 dapat menjadi Salah satu pemecahan masalah dalam memprediksi resiko kredit pada koperasi kofipindo lubuk pakam

2. Dengan menggunakan impelementasi algoritma j48 memperoleh hasil rule dengan resiko kredit yang paling berpengaruh adalah pendapatan.

3. Tools yang digunakan untuk mengui hasil prediksi resiko kredit pada koperasi kofipindo menggunakan tools rapid miner.

\section{REFERENCES}

[1] F. J. KAUNANG, “pengembangan Desicion Tree j48 untuk Diagnosis Penyakit Diabetes Melitus,” vol. 5, 2018.

[2] S. Adi, "Prediksi kredit macet melalui perilaku nasabah pada koperasi simpan pinjam dengan menggunakan algoritma C45," vol. $6,2015$.

[3] F. A. Hermawati, Data Mining. Yogyakarta: CV.ANDI OFFSET, 2013.

[4] K. dan E. T. Luthfi, Algoritma data mining. Yogyakarta: CV.ANDI OFFSET, 2009.

[5] K. dan E. T. Luthfi, Algoritma Data Mining. Yogyakarta: CV.ANDI OFFSET, 2009.

[6] S. Haryati, A. SudarsonHaryati, S., Sudarsono, A., \& Suryana, E. (2015). Implementasi Data Mining untuk Memprediksi Masa Studi Mahasiswa

[7] https://www.academia.edu/7712860/Belajar_Data_Mining_dengan_RapidMiner, "Belajar_Data_Mining_dengan_RapidMiner.". 